\title{
ANALISIS FAKTOR YANG BERHUBUNGAN DENGAN KEJADIAN KECELAKAAN KERJA DI PT. SEMEN BOSOWA MAROS
}

\author{
Analysis Of Factors Related To Work Accidents In PT. Cement Bosowa Maros \\ Haderiah ${ }^{1}$, Bella Safira ${ }^{2}$ \\ 1,2Jurusan Kesehatan Lingkungan Poltekkes Kemenkes Makassar \\ Bella.s72@gmail.com
}

\begin{abstract}
Operations carried out in the cement industry are very prone to work accidents, accidents that occur in a company are unwanted events. Therefore workplace accidents should be avoided or prevented as much as possible because it can lead to death, disability and material losses. This study aims to determine the factors associated with the incidence of workplace accidents in PT. Bosowa Maros, this type of research is observational analytic with cross sectional approach. The sampling technique or used is cluster random sampling. Sampling in this study were workers who worked in the production section which amounted to 109 people using the Slovin formula. The results showed that there were $52.30 \%$ work accidents and $47.70 \%$ did not experience work accidents. Chi-Square test results obtained extension data $p=$ $0.001<\alpha=0.05$, then there is a relationship between counseling with the incidence of workplace accidents, health examination data $p=0.004<\alpha=0.05$, then there is a relationship between health checks with the incidence of workplace accidents, and data on the use of PPE $p=0,000<\alpha=0.05$, then there is a relationship between the use of PPE and the incidence of workplace accidents. Lack of attention and enthusiasm of workers in following counseling and health checks and lack of understanding of workers related to the use of PPE that is good and right according to work risk. So it is recommended that monitoring counseling be carried out and monitoring health checks on workers at $P T$ Semen Bosowa Maros and providing understanding to workers regarding the use of PPE that is good and correct according to work risks.
\end{abstract}

Keywords: Work accidents, counseling, health checks, use of PPE.

\section{ABSTRAK}

Kegiatan operasi yang dilakukan didalam industri semen sangat rawan terhadap kecelakaan kerja, kecelakaan yang terjadi disuatu perusahaan adalah kejadian yang tidak diinginkan. Oleh karena itu kecelakaan kerja semaksimal mungkin harus dihindari atau dicegah karena dapat mengakibatkan kematian, cacat tubuh serta kerugian material.Penelitian ini bertujuan Untuk mengetahui faktor yang berhubungan dengan kejadian kecelakaan kerja di PT.Semen Bosowa Maros, jenis peneltian ini adalah observasional analitik dengan pendekatan cross sectional. Teknik sampling atau yang digunakan adalah cluster random sampling. Pengambilan sampel dalam penelitian ini adalah pekerja yang bekerja pada bagian produksi yang berjumlah 109 orang dengan menggunakan rumus slovin. Hasil penelitian didapatkan hasil pernah mengalami kecelakaan kerja sebanyak $52,30 \%$ dan tidak mengalami kecelakaan kerja sebanyak 47,70\%. Hasil uji Chi-Square diperoleh data penyuluhan $p=0,001<\alpha=0,05$, ada hubungan antara penyuluhan dengan kejadian kecelakaan kerja, data pemeriksaan kesehatan $p=0,004<\alpha=0,05$, ada hubungan pemeriksaan kesehatan dengan kejadian kecelakaan kerja, dan data penggunaan $\mathrm{APD} p=0,000<\alpha=0,05$, ada hubungan antara penggunaan APD dengan kejadian kecelakaan kerja.Kurangnya perhatian dan antusias pekerja dalam mengikuti penyuluhan dan pemeriksaan kesehatan dan kurangnya pemahaman pekerja terkait penggunaan APD yang baik dan benar sesuai risiko kerja. Sehingga disarankan agar melakukan pemantauan penyuluhan dan melakukan pemantauan pemeriksaan kesehatan pada pekerja PT Semen Bosowa Maros serta memberikan pemahaman kepada pekerja terkait penggunaan APD yang baik dan benar sesuai risiko kerja.

Kata Kunci : Kecelakaan kerja, penyuluhan, pemeriksaan kesehatan, penggunaan APD.

\section{PENDAHULUAN}

Kesehatan sangat penting artinya bagi masyarakat secara umum dan khususnya bagi para karyawan atau buruh atau pekerja yang bekerja pada suatu industri atau perusahaan, mengingat semakin berkembangnya perekonomian dan perindustrian. Di capainya kondisi kesehatan yang optimal adalah sangat penting dan mendasar dalam upaya perkembangan nasional sebab tanpa kondisi tersebut maka produktivitas kerja tidak akan mungkin dapat dicapai, disisi lain produktivitas kerja adalah modal dasar dari suatu pembangunan. (Mulianti ,2005)

Kesehatan Kerja cenderung diartikan sebagai upaya kesehatan yang mengurusi masalah kesehatan secara menyeluruh bagi masyarakat ditempat mereka bekerja, dimana penyuluhan, pemeriksaan kesehatan dan penggunaan Alat Pelindung Diri (APD) pada saat bekerja juga adalah upaya pencegahan terjadinya kecelakaan kerja.

Dalam rangka penerapan system manajemen kecelakaan dan penyakit akibat kerja maka penting diadakannya penerapan system manajemen keselamatan dan kesehatan kerja (Selyanti, 2014). Dilansir pada berita Indotimenews pada 30 oktober 2017 bahwa, terjadi kecelakaan kerja diarea finish mill PT.Semen Bosowa. Hingga berita ini ditayangkan belum ada penjelasan resmi dari pihak PT.Semen Bosowa atas meninggalnya satu karyawan bernama Surman (28 tahun) yang pada saat itu bertugas diarea finish mill. Belajar dari kasus kecelakan yang terjadi pada lingkup perusahan, maka diperlukan suatu kajian atau berupa penelitian terhadap 
factor-faktor apa yang bisa menyebabkan terjadinya kecelakaan pada tenaga kerja .

\section{BAHAN DAN METODE}

\section{Lokasi Penelitian}

Penelitian dilakukan di Pabrik Semen PT. Semen Bosowa Maros yang berlokasi diwilayah kabupaten Maros tepatnya di Desa Baruga Kecamatan Bantimurung yang berjarak kurang lebih $50 \mathrm{~km}$ kota Makassar.

2. Desain dan Variabel Penelitian

a. Desain Penelitian

Jenis peneltian merupakan observasional analitik dengan pendekatan cross sectional, yaitu jenis penelitian yang menekankan pada waktu pengukuran atau obseravasi data dalam satu kali pada waktu yang dilakukan pada varibel terikat dan variable bebas, pendekatan ini digunakan untuk melihat hubungan antara variable satu dengan varibel lainnya.

b. Variabel Penelitian

1. Variabel Bebas

Penyuluhan

Pemeriksaan Kesehatan

Penggunaan APD

2. Variabel Terikat Kejadian Kecelakaan Kerja

3. Variabel Penggangu

Tingkat Pendidikan

Perilaku karyawan

Pengetahuan

c. Populasi dan Sampel

a. Populasi

Populasi dalam penelitian ini adalah pekerja yang bekerja dibagian produksi yang berjumlah 150 orang.

b. Sampel

Teknik sampling atau pengambilan sampel yang digunakan adalah cluster sample. Sampel dalam penelitian ini adalah pekerja yng bekerja pada bagian produksi yang berjumlah 109 orang, yang diambil dengan menggunakan rumus slovin :

$$
\begin{aligned}
& \mathrm{n}=\frac{\mathrm{N}}{1+\mathrm{N}\left(\mathrm{d}^{2}\right)} \\
& \text { Keterangan } \\
& \mathrm{N}=\text { Besarnya sampel } \\
& \mathrm{n}=\text { Besarnya sampel } \\
& \mathrm{d}=\text { Tingkat kepercayaan } \\
& \text { ketepatan yang diinginkan }(0,05)
\end{aligned}
$$

$$
\begin{aligned}
& \mathrm{n}=\frac{\mathrm{N}}{1+\mathrm{N}\left(\mathrm{d}^{2}\right)} \\
& \mathrm{n}=\frac{150}{1+150\left(0,05^{2}\right)} \\
& \mathrm{n}=\frac{150}{1,375} \\
& \mathrm{n}=109
\end{aligned}
$$

\section{TEKNIK PENGUMPULAN DATA}

\section{Data Primer}

Teknik pengumpulan data dalam penelitian ini yaitu menggunakan instrument, instrumen yang digunakan pada penelitian ini adalah kuesioner yang disusun oleh peneliti dan kuesioner ini telah dimodifikasi oleh peneliti dan disesuaikan dengan jenis pekerjaan dan perkembangan teori yang ada.

1. Data Primer

Data primer diperoleh dengan cara melakukan wawancara langsung responden dengan responden yaitu karyawan di PT.Semen Bosowa Maros sesuai dengan daftar pertanyaan atau kuesioner yang telah disusun.

2. Data Sekunder

Data sekunder diperoleh dari bagian personalia PT.Semen Bosowa Maros

3. Pengolahan dan Analisa Data Data yang terkumpul diolah secara manual dan dianalisa secara statik yaitu analisa bivariat. Analisa bivariat adalah analisis yang digunakan untuk mengetahui hubungan antara variable bebas dengan variable terikat menggunakan uji statistik, uji statistik yang digunakan dalam penelitian ini adalah uji ChiSquare :

HASIL

Berdasarkan hasil penelitian, data yang diperoleh dari hasil survey dan observasi yang dilaksanakan, diperoleh hasil tentang Analisis Faktor Yang Berhubungan Dengan Kejadian Kecelakaan Kerja di PT Semen Bosowa Maros.Penelitian ini dilaksanakan pada tanggal 2 Maret - 2 Mei 2019 dengan lokasi Penelitian di PT Semen Bosowa Maros Kabupaten Maros, dengan menggunakan kuesioner dan observasi terhadap responden sebanyak 109 responden, responden yang menjadi sampel penelitian adalah responden yang bekerja pada bagian produksi. Adapun hasil penelitian berdasarkan data dari kuesioner dan observasi akan disajikan dalam bentuk table dan naskah sebagai berikut : 
Jurnal Sulolipu : Media Komunikasi Sivitas Akademika dan Masyarakat

Vol. 20 No.2 2020

e-issn : 2622-6960, p-issn : 0854-624X

\section{Karakteristik Responden}

Tabel 1

Kejadian Kecelakaan Kerja

PT Semen Bosowa Maros Kabupaten Maros Tahun 2019

\begin{tabular}{llll}
\hline $\mathrm{N}$ & $\begin{array}{l}\text { Kejadian Kecelakaan } \\
\mathrm{O}\end{array}$ & $\mathrm{n}$ & $\%$ \\
\hline 1 & Perja & 57 & $\begin{array}{l}52,30 \\
\%\end{array}$ \\
\hline 2 & Tidak Pernah Mengalami & 52 & $\begin{array}{l}47,70 \\
\%\end{array}$ \\
\hline Total & $\begin{array}{l}10 \\
9\end{array}$ & $100 \%$ \\
\hline
\end{tabular}

Sumber :Data Primer

Berdasarkan tabel 5.1 bahwa pekerja sebanyak 57 (52,30 \%) yang mengalami kecelakaan kerja dan $52(47,70 \%)$ yang tidak mengalami kecelakaan kerja. Adapun jenis kecelakaan kerja yang dialami yaitu terjepit alat, terjatuh, tertimpa benda jatuh, tertumbuk, terbakar dan terpotong.

Tabel 2

Penyuluhan Kesehatan PT Semen Bosowa Maros Kabupaten Maros Tahun 2019

\begin{tabular}{cccc}
\hline No & Penyuluhan Kesehatan & $\mathrm{N}$ & $\%$ \\
\hline 1 & Pernah Mengikuti & 66 & $60,55 \%$ \\
\hline 2 & Tidak Pernah Mengikuti & 43 & $39,45 \%$ \\
\hline & Total & 109 & $100 \%$
\end{tabular}

Sumber :Data Primer

Berdasarkan tabel 5.2 bahwa pekerja sebanyak $66 \quad(60,55 \%) \quad$ yang pernah mengikuti penyuluhan dan $43(39,45 \%)$ yang tidak pernah mengikuti penyuluhan. Adapun materi penyuluhan yang diberikan kepada karyawan yaitu tentang penggunaan APD, kedisiplinan kerja dan keselamatan dan kesehatan kerja (K3).

Tabel 3

Pemeriksaan Kesehatan PT Semen Bosowa Maros Kabupaten Maros Tahun 2019

\begin{tabular}{cccc}
\hline No & Pemeriksaan Kesehatan & N & $\%$ \\
\hline 1 & Pernah melakukan & 78 & $71,55 \%$ \\
\hline 2 & Tidak Pernah Melakukan & 31 & $28,45 \%$ \\
\hline & Total & 109 & $100 \%$
\end{tabular}

Sumber :Data Primer

Berdasarkan tabel 5.3 bahwa pekerja sebanyak $78 \quad(71,55 \%) \quad$ yang pernah melakukan pemeriksaan kesehatan dan 31
$(28,45 \%)$ yang tidak pernah melakukan pemeriksaan kesehatan. Dari 109 pekerja, semua pernah melakukan pemeriksaan kesehatan sebelum bekerja sebagai pekerja. Adapun pemeriksaan kesehatan yang dilaksanakan oleh perusahaan yaitu setiap satu kali setahun.

Tabel 4

Penggunaan Alat Pelindung Diri (APD)PT Semen Bosowa Maros Kabupaten MarosTahun 2019

\begin{tabular}{cccc}
\hline No & Penggunaan APD & $\mathrm{n}$ & $\%$ \\
\hline 1 & Menggunakan APD & 20 & $18 \%$ \\
\hline 2 & Tidak Menggunakan & 89 & $82 \%$ \\
\hline & Total & 109 & $100 \%$
\end{tabular}

Sumber :Data Primer

Berdasarkan tabel 5.4 bahwa pekerja sebanyak 20 (18\%) yang menggunakan APD sesuai risiko kerja dan pekerja sebanyak 89 (82\%) tidak menggunakan APD sesuai risiko kerja.Penggunaan Alat Pelindung Diri (APD).

Tabel 5

Distribusi Berdasarkan Penggunaan Alat Pelindung Diri Bagian Produksi PT Semen Bosowa MarosTahun 2019

\begin{tabular}{|c|c|c|c|c|}
\hline No & $\begin{array}{l}\text { Jenis } \\
\text { APD }\end{array}$ & Menggunakan & $\mathrm{N}$ & $\%$ \\
\hline 1 & $\begin{array}{l}\text { Helm } \\
\text { Safety }\end{array}$ & Ya & 109 & $100 \%$ \\
\hline 2 & $\begin{array}{l}\text { Ear } \\
\text { plug }\end{array}$ & $\overline{Y a}$ & 1 & $0,91 \%$ \\
\hline
\end{tabular}

Pada tabel 5.5 diketahui bahwa pekerja bagian produksi APD yang banyak digunakan adalah helm safety dan sepatu safety, yaitu sebanyak 109 pekerja (100\%) dan yang paling sedikit digunakan yaitu ear plug yaitu 1 pekerja $(0,91 \%)$.

\section{PEMBAHASAN}

\section{Hubungan Kesehatan Kecelakaan Kerja.

$$
\begin{array}{rr}
\text { faktor } & \begin{array}{r}
\text { Penyuluhan } \\
\text { dengan }
\end{array} \\
\text { Kejadian }
\end{array}
$$

Penyuluhan kesehatan adalah gabungan berbagai kegiatan dan kesempatan yang berlandaskan prinsipprinsip belajar untuk mencapai suatu keadaan, dimana individu, keluarga, kelompok atau masyarakat secara keseluruhan ingin hidup sehat, tahu bagaimana caranya dan melakukan apa yang bisa dilakukan, secara perseorangan maupun secara kelompok dan meminta pertolongan (Effendy, 2010).

Berdasarkan Uji statistik ChiSquare diperoleh nilai $p=0,01$ dan $\alpha=$ 
0,05 dengan tingkat keyakinan $95 \%$. Hal ini menunjukkan bahwa $p<0,05$ dapat disimpulkan $\mathrm{Ha}$ diterima berarti ada hubungan antara penyuluhan dengan kecelakaan kerja pada karyawan PT Semen Bosowa Maros. Hal ini sejalan dengan penelitian yang dilakukan oleh, Mulianti (2005) yang menyatakan ada hubungan antara penyuluhan dengan kecelakaan kerja serta sejalan dengan hasil penelitian Sari Buana (2004) dalam Mulianti (2005) yang menyatakan ada hubungan penyuluhan dengan kecelakaan kerja.Sesuai hasil penelitian dapat diketahui hubungan antara penyuluhan kesehatan dengan kejadian kecelakaan kerja pada karyawan yang bekerja pada bagian produksi di PT Semen Bosowa Maros Kabupaten Maros, dari 109 responden yang mengikuti penyuluhan dan tetap mengalami kecelakaan kerja sebanyak 43 pekerja $(39,45 \%)$ dan tidak mengalami kecelakaan kerja sebanyak 14 pekerja (12,85\%). Responden yang tidak mengikuti penyuluhan dan mengalami kecelakaan kerja sebanyak 23 pekerja $(21,10 \%)$ dan tidak mengalami kecelakaan kerja sebanyak 29 pekerja $(26,60 \%)$.

Penyuluhan

mempunyai

hubungan terhadap kecelakaan kerja hal ini disebabkan oleh kurangnya perhatian pekerja dan kemauan pekerja dalam mengikuti penyuluhan, dan dari hasil penelitian didapatkan persentase tertinggi yaitu mengikuti penyuluhan dan tetap mengalami kecelakaan kerja sebanyak 43 pekerja $(39,45 \%)$ hal ini disebabkan kurangnya perhatian pekerja dan kemauan pekerja dalam mengikuti dan menerapkan ilmu yang didapatkan pada saat penyuluhan, dan responden yang tidak mengikuti penyuluhan dan tidak mengalami kecelakaan kerja sebanyak 29 pekerja $(26,60 \%)$, hal ini membuktikan bahwa tidak semua yang tidak mengikuti penyuluhan mengalami kecelakaan kerja, kecelakaan kerja bisa disebabkan oleh faktor perilaku dan sikap pekerja.Penyuluhan diprediksi dapat merubah perilaku pekerja, contohnya dalam menggunakan APD, pekerja ketika bekerja dibagian packer tidak menggunakan masker jadi menggunakan masker.

Selama proses penyuluhan, penyuluhan yaitu metode satu arah dan metode dua arah dengan media elektronik berupa proyektor. Metode satu arah terjadi ketika penyuluh menyampaikan materi kepada responden dengan media slide dan pemutaran video mengenai jenis-jenis APD dan kecelakaan kerja, dan metode dua arah terjadi ketika sesi tanya jawab dilaksanakan antar penyuluh dengan responden. Saat pelaksanaan penyuluhan semua berjalan kondusif, namun masih ada pekerja yang kurang menyimak materi saat penyuluhan berlangsung, sehingga bisa dikaitkan dengan hubungan kejadian kecelakaan kerja yang terjadi pada pekerja dikarenakan pekerja yang mengikuti penyuluhan tapi kurang menyimak pada saat penyuluh memberi penyuluhan dan didapatkan hasil 43 pekerja $(39,45 \%)$ yang mengikuti penyuluhan tapi tetap mengalami kejadian kecelakaan kerja dan masih banyak pekerja yang tidak menghadiri penyuluhan, hal ini disebabkan oleh perilaku pekerja, Menurut Notoatmodjo (2003) upaya intervensi terhadap faktor perilaku dapat dilakukan melalui dua pendekatan, yaitu pendidikan atau paksaan/tekanan, dalam hal ini paksaan/tekanan dari pihak perusahaan tidak memiliki efek jera terhadap pekerja, pasalnya tidak ada sanksi yang diberikan kepada pekerja bila tidak mengikuti penyuluhan yang sudah dijadwalkan.

Sementara itu penyuluhan kesehatan diartikan sebagai kegiatan pendidikan kesehatan yang dilakukan dengan cara menyebarluaskan pesan dan menanamkan keyakinan Azwar (1983) dalam Maulana (2009).

Adapun variable penganggu
adalah tingkat Pendidikan dan pengetahuan, dimana rata rata pekerja di PT Semen Bosowa berpendidikan rendah, menurut Effendi (2010) Pendidikan dapat mempengaruhi cara pandang seseorang terhadap informasi baru yang diterimanya. Maka dapat dikatakan bahwa semakin tinggi tingkat pendidikannya, semakin mudah seseorang menerima informasi yang didapatnya. Dan untuk pengetahuan pekerja, pengetahuan pekerja dalam hal ini adalah pengetahuan yang diperoleh dari penyuluhan untuk mengurangi risiko kecelakaan kerja, tidak adanya jaminan 
bahwa tenaga kerja yang memiliki pengetahuan tinggi akan patuh terhadap penyuluhan yang diberikan karena pengetahuan yang dimiliki tenaga kerja hanya sampai pada pengetahuan tingkatan pertama. Menurut Notoatmodjo (2003), pengetahuan tingkat pertama merupakan pengetahuan yang sekedar mengingat informasi yang diterima.

\section{Hubungan faktor Pemeriksaan Kesehatan dengan Kejadian Kecelakaan Kerja. \\ Demi terciptanya produktifitas} optimal, dilaksanakan pemeriksaan kesehatan, di PT Semen Bosowa terdapat klinik khusus untuk memeriksa kondisi pekerja jika terdapat keluhan, jika pekerja bekerja dalam keadaan tidak sehat akan memungkinkan terjadinya kecelakaan kerja, seperti yang terjadi pada salah satu pekerja, didapatkan dari sumber laporan kecelakaan kerja PT Semen Bosowa tahun 2019 telah terjadi kecelakaan kerja (Fatality) dikarenakan pekerja terjatuh dari atap mobil pada saat membuka menhole mobil, akibatnya memar dibagian kepala, keterangan dari evaluation safety section head Irsan idris mengatakan bahwa pekerja tersebut diduga pusing karena kekurangan darah dan tetap memaksakan untuk bekerja sehingga terjadi kecelakaan kerja. Berdasarkan hasil penelitian dapat diketahui hubungan antara pemeriksaan kesehatan dengan kejadian kecelakaan kerja pada karyawan yang bekerja pada bagian produksi di PT Semen Bosowa Maros Kabupaten Maros, dari 109 responden yang melakukan pemeriksaan kesehatan dan tetap mengalami kecelakaan kerja sebanyak 34 pekerja $(31,20 \%)$ dan tidak mengalami kecelakaan kerja sebanyak 23 pekerja $(21,10 \%)$. Responden yang tidak melakukan pemeriksaan kesehatan dan mengalami kecelakaan kerja sebanyak 44 pekerja $(40,37 \%)$ dan tidak mengalami kecelakaan kerja sebanyak 8 pekerja $(7,33 \%)$.

Berdasarkan Uji statistik ChiSquare diperoleh nilai $p=0,04$ dan $\alpha=$ 0,05 dengan tingkat keyakinan $95 \%$. Hal ini menunjukkan bahwa $p<0,05$ dapat disimpulkan $\mathrm{Ha}$ diterima berarti ada hubungan antara penyuluhan dengan kecelakaan kerja pada karyawan PT Semen Bosowa Maros. Hal ini sejalan dengan penelitian yang dilakukan oleh Mulianti (2005) yang menyatakan ada hubungan antara pemeriksaan kesehatan dengan kecelakaan kerja serta sejalan dengan hasil dari penelitian Sari Buana (2004) dalam Mulianti (2005) yang menyatakan ada hubungan antara pemeriksaan kesehatan dengan kecelakaan kerja.

Dalam penelitian ini pekerja yang tidak melakukan pemeriksaan kesehatan dan mengalami kecelakaan kerja adalah sebanyak 44 pekerja dan angka tersebut masih terbilang tinggi. $\mathrm{Hal}$ ini membuktikan bahwa ada hubungan antara pemeriksaan kesehatan dengan kejadian kecelakaan kerja, dan berdasarkan hasil wawancara dengan petugas safety pekerja yang mengalami gangguan kesehatan diharapkan untuk beristirahat dan memeriksakan kesehatannya diklinik perusahaan atau dilayanan kesehatan lainnya, namun banyak yang mengabaikan intruksi dari petugas safety.

Pemeriksaan kesehatan pada pekerja di PT Semen Bosowa dilakukan secara berkala selama setahun sekali, dan pemeriksaan kesehatan juga diberikan kepada calon pekerja baru. Masih ada pekerja yang melewatkan pemeriksaan berkala dengan alasan tidak memiliki keluhan kesehatan apapun hal ini disebabkan oleh kurangnya pengetahuan atau sumber informasi yang mereka dapatkan baik dalam Pendidikan maupun lingkungan. Dan ruang lingkup para karyawan bagian produksi di PT Semen Bosowa sehingga pengetahuan mereka kurang.

3. Hubungan faktor Penggunaan APD dengan Kejadian Kecelakaan Kerja. Alat Pelindung Diri (APD) adalah seperangkat alat keselamatan yang digunakan oleh pekerja untuk melindungi seluruh atau sebagian tubuhnya dari kemungkinan adanya pemaparan potensi bahaya lingkungan dari PAK dan kecelakaan kerja. Penggunaan APD merupakan tingkat pengendalian resiko kerja paling akhir dan murah, diharapkan dengan penggunaan APD dapat mencegah atau meminimalkan terjadinya kecelakaan dan penyakit akibat kerja adapun dampak yang terjadi bila pengunaan APD tidak diterapkan dilingkungan kerja seperti pengunaan 
APD.Contoh kasus yaitu penggunaan APD kacamata safety, di PT Semen Bosowa banyak sekali potensi bahaya yang bisa menyebabkan iritasi pada mata disebabkan oleh penyemprotan $\mathrm{HCL}$, dan penyemprotan material semen, penggunaan APD memang tidak dapat mencegah terjadinya kecelakaan kerja tapi dapat meminimalkan efek dari kecelakaan yang diderita.

Berdasarkan data kecelakaan kerja PT Semen Bosowa tahun 2018 sampai dengan 2019 tercatat 6 pekerja yang mengalami kecelakaan kerja akibat iritasi mata, contohnya yang dialami salah satu pekerja pada tanggal 17 Februari 2019,pekerja tersebut bekerja pada bagian produksi packer dan mengalami cedera pada mata, hal ini disebabkan karena pada saat membuka gatespot tiba tiba material menyembur ke arah mata akibatnya pekerja tersebut mengalami cedera pada mata dan tidak bisa melanjutkan pekerjaan. Pada saat wawancara dengan evaluation safety section head Irsan idris didapatkan informasi bahwa pekerja tersebut tidak menggunakan kacamata safety pada saat bekerja. Berdasarkan contoh kasus diatas maka dapat diketahui bahwa penggunaan alat pelindung diri (APD) sangat berhubungan dengan kejadian kecelakaan kerja.

Berdasarkan hasil uji statistik Chi-Square, maka diperoleh $\mathrm{p}=0,000<$ $\alpha=0,05$, maka Ha diterima berarti ada hubungan antara pemeriksaan kesehatan dengan kecelakaan kerja pada karyawan PT Semen Bosowa Maros.

Berdasarkan hasil uji Chi-Square dapat diketahui hubungan antara penggunaan APD dengan kejadian kecelakaan kerja pada pekerja yang bekerja pada bagian produksi di PT Semen Bosowa Maros Kabupaten Maros, dari 109 responden yang menggunakan APD dan tetap mengalami kecelakaan kerja sebanyak 20 pekerja (18,34\%) dan tidak mengalami kecelakaan kerja sebanyak 0 pekerja (0\%). Pekerja yang tidak menggunakan APD dan mengalami kecelakaan kerja sebanyak 37 pekerja $(33,95 \%)$ dan tidak mengalami kecelakaan kerja sebanyak 52 pekerja $(47,71 \%)$. Hal ini sejalan dengan penelitian yang dilakukan oleh Mulianti
(2005) yang menyatakan ada hubungan antara penggunaan APD dengan kecelakaan kerja serta sejalan dengan hasil dari penelitian Sari Buana (2004) dalam Mulianti (2005) yang menyatakan ada hubungan antara penggunaan APD dengan kecelakaan kerja.

Berdasarkan observasi banyak pekerja yang tidak menggunakan APD sesuai dengan faktor risiko kerja yang dikerjakan, dan pada saat penyuluhan berlangsung terdapat pekerja yang mengajukan keluhan terhadap kualitas APD, banyak pekerja yang menggunakan sepatu safety yang sudah tidak layak pakai, dari perusahaan sudah menyiapkan APD untuk pekerja, dan diberikan setahun sekali, namun menurut petugas safety yang bertanggung jawab meskipun sudah diberikan yang baru pekerja tetap menggunakan yang lama, menurut informasi dari pekerja yang lain, banyak pekerja yang menjual kembali APD yang dibagikan oleh perusahaan, sehingga pekerja tetap menggunakan APD yang rusak untuk bekerja.

Berdasarkan observasi yang dilakukan selama penelitian masih ada karyawan yang bekerja tidak menggunakan APD sesuai dengan risiko kerja. Demi menghindari kecelakaan kerja petugas safey memasang sedemikian rupa rambu rambu K3 berupa penggunaan APD wajib pada bagian bagian tertentu, misalnya pada bagian raw mill yang diwajibkan menggunakan ear plug tapi karyawan yang bekerja pada bagian Raw Mill tidak menggunakan ear plug hanya menutup telinga saja pada saat dilokasi raw mill, dan pada bagian packer para pekerja diwajibkan menggunakan masker dan sarung tangan tapi masih banyak pekerja yang tidak menggunakan masker pada saat bekerja dengan alasan tidak nyaman saat menggunakannya, menurut Ridley (2008) mengatakan bahwa salah satu syarat APD adalah nyaman untuk digunakan bagi penggunanya, dan pekerja yang tidak menggunakan sarung tangan hal ini bisa dikarenakan pekerja merasakan kesulitan ketika bekerja menggunakan sarung tangan serta ketidaknyamanan pengguna, dan banyak pekerja yang tidak menggunakan pakaian kerja pada saat bekerja dengan alasan tidak nyaman saat 
menggunakannya dan tidak disediakan oleh perusahaan.

Menurut Reason (1997) dalam Halimah (2010) pekerja hendaknya memiliki kesadaran atas keadaan yang berbahaya sehingga risiko terjadinya kecelakaan kerja dapat diminimalisir. Kesadaran terhadap bahaya yang mengancam dapat diwujudkan dengan mematuhi prosedur dan peraturan yang berlaku dengan bekerja sesuai tanggung jawab. Penelitian ini sesuai dengan pendapat Geller (2001) kepatuhan adalah salah satu bentuk perilaku yang dipengaruhi faktor internal maupun faktor eksternal yang sesuai dengan ketentuan yang berlaku.

\section{Analisis Hubungan Antar variable}

Hasil uji statistic Chi-Square yang dilakukan maka diperoleh $p=0,011$ $<\alpha=0,05$. Maka Ha diterima berarti ada hubungan antara penyuluhan dengan kecelakaan kerja pada karyawan PT Semen Bosowa Maros.Berdasarkan tabel 5.6 dapat diketahui hubungan antara penyuluhan kesehatan dengan kejadian kecelakaan kerja pada pekerja yang bekerja pada bagian produksi di PT Semen Bosowa Maros Kabupaten Maros, dari 109 pekerja yang mengikuti penyuluhan dan tetap mengalami kecelakaan kerja sebanyak 43 pekerja $(39,45 \%)$ dan tidak mengalami kecelakaan kerja sebanyak 14 pekerja $(12,85 \%)$. Pekerja yang tidak mengikuti penyuluhan dan mengalami kecelakaan kerja sebanyak 23 pekerja $(21,10 \%)$ dan tidak mengalami kecelakaan kerja sebanyak 29 pekerja $(26,60 \%)$.

Hasil uji statistik Chi-Square yang dilakukan maka diperoleh $p=0,000$ $<\alpha=0,05$. Maka Ha diterima berarti ada hubungan antara pemeriksaan kesehatan dengan kecelakaan kerja pada karyawan PT Semen Bosowa Maros.

Berdasarkan tabel 5.7 dapat diketahui hubungan antara pemeriksaan kesehatan dengan kejadian kecelakaan kerja pada pekerja yang bekerja pada bagian produksi di PT Semen Bosowa Maros Kabupaten Maros, dari 109 pekerja yang melakukan pemeriksaan kesehatan dan tetap mengalami kecelakaan kerja sebanyak 34 pekerja $(31,20 \%)$ dan tidak mengalami kecelakaan kerja sebanyak 23 pekerja $(21,10 \%)$. Pekerja yang tidak melakukan pemeriksaan kesehatan dan mengalami kecelakaan kerja sebanyak 44 pekerja $(40,37 \%)$ dan tidak mengalami kecelakaan kerja sebanyak 8 pekerja (7,33\%).

Berdasarkan tabel 5.8 hasil uji statistik Chi-Square, maka diperoleh $\mathrm{p}=$ $0,000<\alpha=0,05$, maka Ha diterima berarti ada hubungan antara pemeriksaan kesehatan dengan kecelakaan kerja pada karyawan PT Semen Bosowa Maros.

Berdasarkan tabel 5.8 dapat diketahui hubungan antara penggunaan APD dengan kejadian kecelakaan kerja pada pekerja yang bekerja pada bagian produksi di PT Semen Bosowa Maros Kabupaten Maros, dari 109 responden yang menggunakan APD dan tetap mengalami kecelakaan kerja sebanyak 20 pekerja $(18,34 \%)$ dan tidak mengalami kecelakaan kerja sebanyak 0 pekerja (0\%). Pekerja yang tidak menggunakan APD dan mengalami kecelakaan kerja sebanyak 37 pekerja $(33,95 \%)$ dan tidak mengalami kecelakaan kerja sebanyak 52 pekerja $(47,71 \%)$.

\section{KESIMPULAN DAN SARAN \\ KESIMPULAN}

Berdasarkan hasil penelitian yang telah dilakukan tentang analisis faktor yang berhubungan dengan kejadian kecelakaan kerja di PT Semen Bosowa Maros, dapat disimpulkan sebagai berikut :

1. Ada hubungan antara faktor penyuluhan dengan kejadian kecelakaan kerja di PT Semen Bosowa Maros.

2. Ada hubungan antara faktor pemeriksaan kesehatan dengan kejadian kecelakaan kerja di PT Semen Bosowa Maros.

3. Ada hubungan antara faktor penggunaan Alat Pelindung Diri (APD) dengan kejadian kecelakaan

\section{SARAN} kerja di PT Semen Bosowa Maros.

1. Diharapkan adanya pemantauan tentang penyuluhan pekerja, agar pekerja lebih giat mengikuti penyuluhan.

2. Diharapkan adanya pemantauan tentang pemeriksaan kesehatan pekerja secara berkala guna menghindari kejadian kecelakaan kerja. 
Jurnal Sulolipu : Media Komunikasi Sivitas Akademika dan Masyarakat

Vol. 20 No.2 2020

e-issn : 2622-6960, p-issn : 0854-624X

3. Diharapkan kepada pihak perusahaan untuk lebih memberikan pemahaman kepada pekerja terkait penggunaan
APD yang baik dan benar sesuai dengan risiko kerja.

\section{DAFTAR PUSTAKA}

Argama. Rizky.. 2006. Keselamatan dan Kesehatan Kerja Sebagai Komponen Jamsostek, Fakultas Hukum Universitas Indonesia.https://mafiadoc.com/queue/kesehatan-dankeselamatan-kerja-sebagai-komponen-argama_5a01a5691723dd70a2b54b38.html (Diakses 16 Januari 2019)

Budiono. Sugeng.. 2003. Bunga Rampai Hiperkes Dan Keselamatan Kerja, http://lib.ui.ac.id/detail?id=85889\&lokasi=lokal\# (diakses 16 Januari 2019)

Daryanto. 2010. Keselamatan Kerja Peralatan Bengkel Dan Perawatan Mesin,Bandung.http://library.um.ac.id/freecontents/download/pub/downloadprint5.php/40016.pdf. (Diakses 16 Januari 2019)

Baso. Andi.. 2017 Data Kasus Kecelakaan di Indonesia, https://indotimnews.com/adakaryawan-pt-semen-bosowa-tewas-di-tempat-ia-bekerja-sayang-belum-adapenjelasan-dari-pihak-perusahaan/. (Diakses 16 Januari 2019).

Effendy. N. 2010. Dasar-Dasar Keperawatan Kesehatan Masyarakat. Yogyakarta : Rineka Cipta.

Firmansyah. Abdus Salam.. 2015. Fungsi Komunikasi Penyuluhan Dalam Meningkatkan Hasil Panen Petani Pada Petani Sawah Kecamatan Bungaraya Kabupaten Siak Sriindrapura. (diakses pada 2 Desember 2019)

Febyana. Dkk.. 2012. Penerapan Sistem Manajemen Keselamatan Dan Kesehatan Kerja (Smk3) Pada Proyek Konstruksi Di Indonesia (Studi Kasus: Pembangunan Jembatan Dr. Ir. Soekarno-manado). https://ejournal.unsrat.ac.id/index.php/jime/article/view/4232 (Diakses 28 Desember 2018)

Geller. E. Scott. 2001. The Psychology Of Safety Handbook. https://trove.nla.gov.au/work/16093811?q\&versionld=44701690 (Diakses 2 Juni 2019)

Halimah, Siti.. 2010. Faktor-Faktor Yang Mempengaruhi Perilaku Aman Karyawan Di Area Produksi PT.SIM Tambun II tahun 2010. https://docplayer.info/69191935-Faktorfaktor-yang-mempengaruhi-perilaku-aman-skripsi-oleh-siti-halimah-program-studikesehatan-masyarakat-fakultas-kedokteran-dan-ilmu-kesehatan.html (Diakses 2 Juni 2019)

Hassanudin.Amir..2018. Rapor K3 Nasional 2018 Dalam Rangka Menyambut BulanK3, Isafetymagazine.https://www.scribd.com/document/373380451/Isafety-EdisiJanuari-Wa (Diakses 14 Februari 2019)

Ibrahim. Hasbi. Dkk.. 2016. Gambaran Faktor Risiko Kecelakaan Kerja Pada Departemen Produksi Bahan Baku di PT.Semen Tonasa Kabupaten Pangkep,http://journal.uinalauddin.ac.id/index.php/Al-Sihah/article/view/3145 (Diakses 14 Februari 2019)

Meily.L..2011.Teori Dan Aplikasi Kesehatan Kerja, file:///C:/Users/HP/Downloads/pdf_metadata20355241.pdf (Diakses 16 Januari 2019)

Mulianti, 2005, Hubungan Penerapan Kesehatan dan Keselamatan Kerja Dengan Kejadian Kecelakaan Kerja di PT.Antam,Tbk-UBPN Pomala Kabupaten Kolak , jurusan Kesehatan Lingkungan Politeknik Kesehatan Makassar (Tidak dipublikasikan

Notoatmodjo, Soekidjo.. 2010, Metodologi Penelitian Kesehatan, https://scholar.google.co.id/citations?user=t4hTra0AAAAJ\&hl=en (Diakses 2 Juni 2019)

Notoatmodjo, Soekidjo.. 2003, Pendidikan Dan Perilaku Kesehatan, https://scholar.google.co.id/citations?user=t4hTra0AAAAJ\&hl=en (Diakses 2 Juni 2019)

Priono.Noviaji..2018 Data Kasus Kecelakaan Di Indonesia. https://sadkes.net/2018/12/30/datakasus-kecelakaan-kerja-di-indonesia/, (Diakses 15 Januari 2019)

Ramli. Soehatman.. 2010. Pedoman Praktis Manajemen Risiko dalam PerspektifK3,http://opac.perpusnas.go.id/DetailOpac.aspx?id=699927 (Diakses 16 Januari 2019) 
Jurnal Sulolipu : Media Komunikasi Sivitas Akademika dan Masyarakat

Vol. 20 No. 22020

e-issn : 2622-6960, p-issn : 0854-624X

Santoso. Gempur..2004 Manajemen Keselamatan dan Kesehatan Kerja https://scholar.google.co.id/citations?user=v09Zt7QAAAAJ\&hl=id (Diakses Desember 2018)

Selyanti. Dkk.. 2014. Gambaran Penerapan Sistem Manajmen Keselamatan Dan Kesehatan Kerja (SMK3) Pada PT.Semen Bosowa Maros, http://repository.unhas.ac.id/handle/123456789/9380 (Diakses 2 Desember 2018)

Sialagan, Togar Robin, 2008. Analisis Faktor-Faktor Yang Berkontribusi Pada Perilaku Aman Di PT.EGS Indonesia Tahun 2008. http://repository.uinjkt.ac.id/dspace/bitstream/123456789/627/1/92636-

SITI\%20HALIMAH-FKIK.pdf (Diakses 2 Desember 2018)

Sriwahyuningsih, 2009. Penerapan Manajemen Keselamatan Kerja Dalam Perusahaan. https://www.neliti.com/id/publications/168520/penerapan-kebijakan-manajemenkeselamatan-kerja-di-dalam-perusahaan. (Diakses pada 18 Juni 2019)

Sucipto. Cecep.. 2014. Keselamatan Dan Kesehatan Kerja. Yogyakarta : gosyen publishing

Suma'mur. 2009. Keselamatan Kerja dan Pencegahan Kecelakaan, https://eprints.uny.ac.id/3548/1/PENGAMANAN_DAN_KESELAMATAN_KERJA.pdf (Diakses pada 2 Desember 2018)

Triwibowo. Cecep. Dkk.. 2013. Kesehatan Lingkungan dan K3, Yogyakarta : Nuha Medika Undang Undang Republik Indonesia Nomor 13. 2003, Ketenagakerjaan, Jakarta.

Wibisono. Bayu.. 2013. Faktor-Faktor Berhubungan Dengan Kejadian Kecelakaan Kerja Pada Pekerja Tambang Pasir Gali Di Desa Pengiringan Kabupaten Pemalang Tahun 2013. http://eprints.dinus.ac.id/6713/ (Diakses 16 Januari 2019) 